\title{
Synthesis and Enhanced Guest-Binding Affinities of Dendrimer-Based Cyclophane Tetramer and Octamer
}

\author{
Osamu Hayashida*, Tomomi Nakashima, Yu Kaku \\ Department of Chemistry, Faculty of Science, Fukuoka University, Fukuoka, Japan \\ Email: "hayashida@fukuoka-u.ac.jp
}

Received March 16, 2013; revised April 16, 2013; accepted May 16, 2013

Copyright (C) 2013 Osamu Hayashida et al. This is an open access article distributed under the Creative Commons Attribution License, which permits unrestricted use, distribution, and reproduction in any medium, provided the original work is properly cited.

\begin{abstract}
Dendritic cyclophane tetramer and octamer were prepared by aminolysis of succinimidyl ester derivative of tetraaza [6.1.6.1] paracyclophane with the corresponding poly(amidoamine) dendrimers as a scaffold, followed by removal of the protecting groups. The present cyclophane tetramer and octamer showed enhanced guest-binding affinities toward fluorescent guests such as 6-p-toluidinonaphthalene-2-sulfonate and 6-anilinonaphthalene-2-sulfonate, in comparison with those of monocyclic cyclophane, reflecting multivalency effects in macrocycles.
\end{abstract}

Keywords: Cyclophane Oligomer; Host-Guest Chemistry; Multivalency Effect

\section{Introduction}

Multivalent clusters of naturally occurring cell-surface receptors are known to exhibit extremely strong binding ability with ligands, although the affinities of monovalent receptors are weak [1,2]. With an aim of performing functional simulation of the cell-surface receptors, we have recently developed pendent-type cyclophane oligomers such as cyclophane dimer, trimer, tetramer, and pentamer, using scaffolds such as lysine and lysine peptides $[3,4]$. We also reported that the present cyclophane oligomers showed enhanced guest-binding affinities toward fluorescent guests such as 6-p-toluidinonaphthalene-2-sulfonate (TNS), in comparison with those of monocyclic cyclophane, reflecting multivalency effects in macrocycles $[3,4]$. For instance, the guest-binding affinity of the cyclophane pentamer with TNS was enhanced about 92-fold relative to that of the corresponding monocyclic cyclophane, as evaluated by fluorescence spectroscopy $[3,4]$. In the course of our ongoing research on cyclophane oligomers, we became interested in developing divergent-type cyclophane oligomers, which provide multiple equivalent binding sites. On the other hand, symmetrical dendrimers are frequently used as a scaffold, because such dendrimers take advantages in a viewpoint of monodispersity [5] and terminal functionalization [6]. On these grounds, in order to get further insights into the guest-binding affinities with emphasis

"Corresponding author. on the multivalent effect on the macrocycles, we have now designed and prepared dendrimer-based cyclophane tetramer and octamer using dendrimers as a scaffold (1 and 2, respectively, Figure 1). We describe herein the synthesis of the dendritic cyclophane tetramer and octamer and their binding affinity with fluorescence guests, as evaluated in aqueous media by means of fluorescence spectroscopy.

\section{Experimental Section}

\subsection{General Methods}

HEPES (N-(2-hydroxyethyl) piperazine-N'-2-ethane- sulfonic acid) buffer $(0.01 \mathrm{M}, \mathrm{pH} 7.4$, with $0.15 \mathrm{M} \mathrm{NaCl})$ was purchased from GE Healthcare. The following compounds were obtained from commercial sources as guaranteed reagents and used without further purification: potassium 6-p-toluidinonaphthalene-2-sulfonate [K (TN$\mathrm{S})$ ] (from Nacalai Tesque, Inc., Kyoto, Japan); 2-anilinonaphthalene-6-sulfonic acid (2,6-ANS) (from Molecular Probes, Eugene, OR); Polyamidoamine dendrimer generation 0, $20 \mathrm{wt} \%$ solution in methanol (3) and polyamidoamine dendrimer generation 1, $20 \mathrm{wt} \%$ solution (4) (all from Sigma-Aldrich Japan, Tokyo, Japan). A succinimidyl ester derivative of cyclophane (5) was prepared after a method reported previously [3]. Elemental analyses were recorded on a Yanako CHN Corder MT-5. ${ }^{1} \mathrm{H}$ and ${ }^{13} \mathrm{C}$ spectra were taken on Varian Mercury 400 spectrometer. Fluorescence spectra, IR spectra, and ESI TOF 

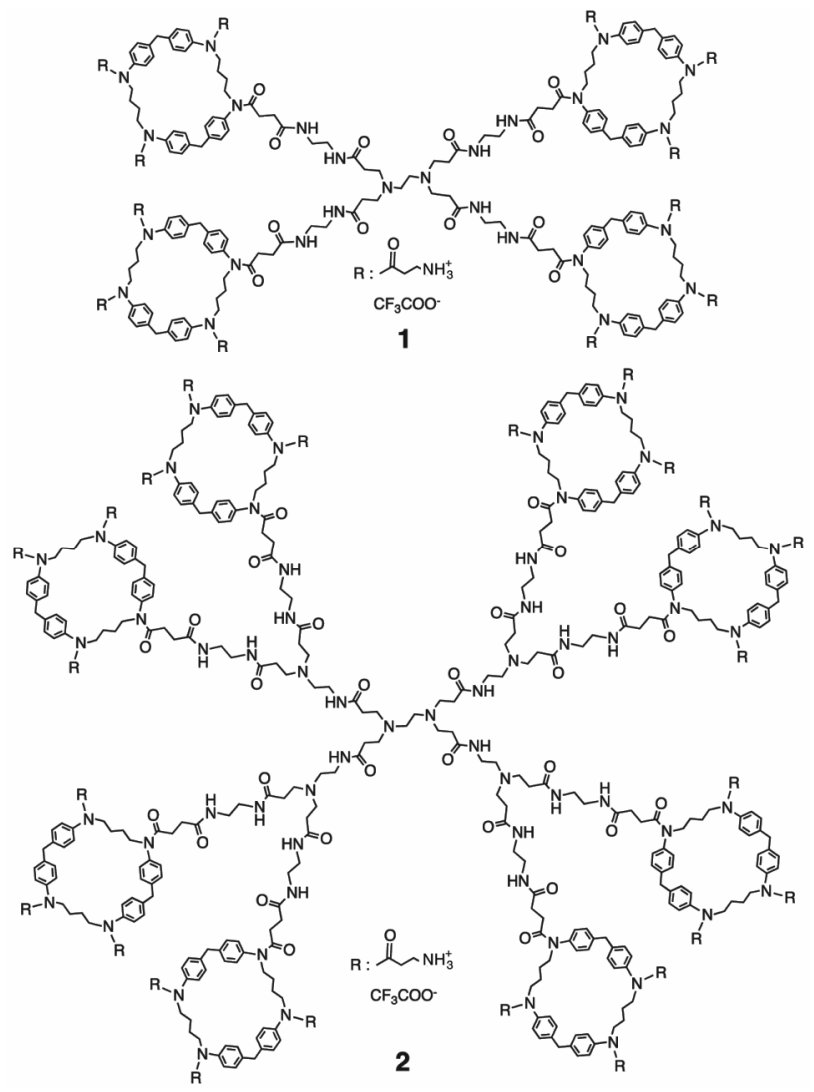

Figure 1. Dendritic cyclophane tetramer 1 and octamer 2.

MS were recorded on Perkin Elmer LS55, Perkin-Elmer spectrum one, and JMS-T100 CS spectrometers, respectively.

\subsection{Precursor of Dendrimer-Based Cyclophane Tetramer (6)}

Polyamidoamine dendrimer generation $0,20 \mathrm{wt} \%$ solution in methanol $(3,138 \mathrm{mg}, 0.053 \mathrm{mmol})$ was evaporated to dryness under reduced pressure. Succinimidyl ester derivative of cyclophane $5(352 \mathrm{mg}, 0.29 \mathrm{mmol})$ was added to a solution of $\mathbf{3}$ in dry N, N-dimethylformamide (DMF, $2.5 \mathrm{ml}$ ) and the mixture was stirred for 3 days at room temperature. The solution was evaporated to dryness under reduced pressure. The crude product was purified by gel filtration chromatography on a column of Sephadex LH-20 with methanol as an eluant. The product fraction was evaporated to dryness under reduced pressure to give a white solid. (185 mg, 71\%): $\mathrm{mp}$ $138.3^{\circ} \mathrm{C}-140.5^{\circ} \mathrm{C} .{ }^{13} \mathrm{C}$ NMR $\left(100 \mathrm{MHz}, \mathrm{CDCl}_{3}, 293 \mathrm{~K}\right)$ $\delta 24.8,28.3,29.8,30.8,31.5,34.7,36.2,38.9,40.1,48.6$, $48.8,49.8,78.8,128.2,130.1,140.1,140.4,155.8,171.3$, 171.6, 172.0, and 173.0. IR 1638, $1702 \mathrm{~cm}^{-1}(\mathrm{C}=\mathrm{O})$. Found: $\mathrm{C}, 65.44 ; \mathrm{H}, 7.55 ; \mathrm{N}$, 10.52. Caled for $\mathrm{C}_{270} \mathrm{H}_{372} \mathrm{~N}_{38} \mathrm{O}_{36} \cdot \mathrm{H}_{2} \mathrm{O}$ : C, 65.70; H, 7.64; N, 10.78 . ESI-TOF MS: m/z 1661.8 $[\mathrm{M}+3 \mathrm{Na}]^{3+}$.

\subsection{Dendrimer-Based Cyclophane Tetramer (1)}

Trifluoroacetic acid (TFA, $0.5 \mathrm{ml}$ ) was added to a solution of compound $6(80 \mathrm{mg}, 0.016 \mathrm{mmol})$ in dry dichloromethane (DCM, $2.5 \mathrm{ml}$ ), and the mixture was stirred for $1 \mathrm{~h}$ at room temperature. After the solvent was evaporated off under reduced pressure, the crude product was purified by gel filtration chromatography on a column of Sephadex LH-20 with methanol as an eluant. The product fraction was evaporated to dryness under reduced pressure to give a white solid. (58 $\mathrm{mg}, 72 \%)$ : $\mathrm{mp}$ $140.0^{\circ} \mathrm{C}-142.1{ }^{\circ} \mathrm{C} .{ }^{13} \mathrm{C}$ NMR $\left(100 \mathrm{MHz}, \mathrm{CDCl}_{3}, 293 \mathrm{~K}\right)$ $\delta 25.5,30.9,31.8,33.1,37.140 .0,41.8,116.8,119.7$, $129.6,131.5,140.8,141.4,142.5,142.8,162.8,163.2$, 171.6, 173.4, and 174.9. IR $1637 \mathrm{~cm}^{-1}(\mathrm{C}=\mathrm{O})$. Found: $\mathrm{C}$, 55.27; $\mathrm{H}, 5.71 ; \mathrm{N}, 10.47$. Calcd for $\mathrm{C}_{234} \mathrm{H}_{288} \mathrm{~F}_{36} \mathrm{~N}_{38} \mathrm{O}_{48}$ : C, 55.57; H, 5.88; N, 10.28. ESI-TOF MS: m/z 1239.3 [M+ $3 \mathrm{H}]^{3+}$, where $\mathrm{M}$ denotes amine derivative of cyclophane as free base.

\subsection{Precursor of Dendrimer-Based Cyclophane Octamer (7)}

Polyamidoamine dendrimer generation 1, $20 \mathrm{wt} . \%$ solution $(4,157 \mathrm{mg}, 0.021 \mathrm{mmol})$ in methanol was evaporated to dryness under reduced pressure. Succinimidyl ester derivative of cyclophane $5(300 \mathrm{mg}, 0.25 \mathrm{mmol})$ was added to a solution of 4 in DMF $(2.5 \mathrm{ml})$ and the mixture was stirred for 10 days at room temperature. The solution was evaporated to dryness under reduced pressure. The crude product was purified by gel filtration chromatography on a column of Sephadex LH-20 with methanol as an eluant. The product fraction was evaporated to dryness under reduced pressure to give a white solid. (201 mg, 94\%): $\mathrm{mp} 137.9^{\circ} \mathrm{C}-140.7{ }^{\circ} \mathrm{C} .{ }^{13} \mathrm{C}$ NMR $\left(100 \mathrm{MHz}, \mathrm{CDCl}_{3}, 293 \mathrm{~K}\right) \delta 24.7,28.2,29.7,30.8,34.5$, $36.1,37.5,38.6,40.8,48.5,50.1,52.1,78.7,128.0,129.9$, $139.9,140.3,155.7,171.2,171.6$, and 172.8. IR 1638, $1702 \mathrm{~cm}^{-1}(\mathrm{C}=\mathrm{O})$. Found: $\mathrm{C}, 64.08 ; \mathrm{H}, 7.65 ; \mathrm{N}, 10.82$. Calcd for $\mathrm{C}_{558} \mathrm{H}_{776} \mathrm{~N}_{82} \mathrm{O}_{100} \cdot 10 \mathrm{H}_{2} \mathrm{O}: \mathrm{C}, 64.36 \mathrm{H}, 7.71 ; \mathrm{N}$, 11.03. ESI-TOF MS: $\mathrm{m} / \mathrm{z} 1300.6[\mathrm{M}+8 \mathrm{Na}]^{8+}$.

\subsection{Dendrimer-Based Cyclophane Octamer (2)}

TFA $(0.5 \mathrm{ml})$ was added to a solution of compound 7 ( 85 $\mathrm{mg}, 0.0083 \mathrm{mmol})$ in DCM $(2.5 \mathrm{ml})$ and the mixture was stirred for $1 \mathrm{~h}$ at room temperature. After the solvent was evaporated off under reduced pressure, the crude product was purified by gel filtration chromatography on a column of Sephadex LH-20 with methanol as an eluant. The product fraction was evaporated to dryness under reduced pressure to give a white solid. (77 mg, $88 \%$ ): $\mathrm{mp}$ $138.6^{\circ} \mathrm{C}-141.3^{\circ} \mathrm{C} .{ }^{13} \mathrm{C}$ NMR $\left(100 \mathrm{MHz}, \mathrm{CD}_{3} \mathrm{OD}, 293 \mathrm{~K}\right)$ $\delta 25.5,30.9,31.8,32.6,37.0,39.8,40.1,41.7,116.8$, $119.7,129.6,131.5,140.7,141.4,142.5,142.9,162.7$, 163.0, 171.4, 173.4, and 175.0. IR $1637 \mathrm{~cm}^{-1}(\mathrm{C}=\mathrm{O})$. 
Found: C, 54.97; H, 5.90; N, 10.91. Calcd for $\mathrm{C}_{486} \mathrm{H}_{608} \mathrm{~F}_{72} \mathrm{~N}_{82} \mathrm{O}_{100}$ : C, 55.24; H, 5.80; N, 10.87. ESITOF MS: $\mathrm{m} / \mathrm{z} 1305.5[\mathrm{M}+6 \mathrm{H}]^{6+}$, where $\mathrm{M}$ denotes amine derivative of cyclophane as free base.

\subsection{Binding Constants of Cyclophane with Fluorescence Guests}

To each solution of a fluorescent guest $(0.25 \mu \mathrm{M})$ in HEPES buffer were added increasing amounts of the hosts at $298 \mathrm{~K}$, and the guest fluorescence intensity was monitored after each addition by excitation at 322 and $318 \mathrm{~nm}$ for TNS and 2,6-ANS, respectively. The binding constants were calculated on the basis of the Benesi-Hildebrand method for titration data.

\section{Results and Discussion}

\subsection{Design and Synthesis of Dendrimer-Based Cyclophane Oligomers}

Dendrimers are attractive scaffold for wide variety of applications such as drug delivery vehicles, catalysts, and sensors [7]. In particular, poly (amidoamine) dendrimers (PAMAN) [8] are the most popular dendrimer for such purpose owing to advantages of its primary amino nature and reactivity. Generation 0 PAMAN dendrimer (3) and generation 1 PAMAN dendrimer (4) have four and eight terminal amino groups, respectively. In order to develop dendrimer-based cyclophane oligomers, we have adopted 3 and 4 , as a scaffold to assemble cyclophane skeletons on. For example, cyclophane tetramer 1 was designed by introducing four cyclophane skeletons onto each primary amino group of $\mathbf{3}$ through an alkyl spacer having amide linkage (Figure 1). Analogous cyclophane octamer 2 were also designed by using $\mathbf{4}$ in place of $\mathbf{3}$, as a scaffold (Figure 1).

Dendritic cyclophane oligomers $\mathbf{1}$ and $\mathbf{2}$ were synthesized by following the reaction sequence shown in Scheme 1. Owing to the reactivity of succinimidyl ester with primary amines, succinimidyl ester derivative of cyclophane 5 [3] was used for the condensation of cyclophanes with the corresponding dendrimers. A precursor of cyclophane tetramer (6) was prepared by aminolysis of 5 with 3 in a 71\% yield. Cyclophane tetramer 1 was prepared by removal of the protecting groups of $\mathbf{6}$ with trifluoroacetic acid (TFA). Cyclophane octamer 2 were also prepared by condensation of 5 with $\mathbf{4}$, followed by removal of the protecting groups in a manner similar to that applied to the synthesis of 1 (Scheme 1). New compounds were characterized by means of spectroscopy (IR, ${ }^{1} \mathrm{H}$ NMR, ${ }^{13} \mathrm{C} \mathrm{NMR}$, and ESI-MS) and elemental
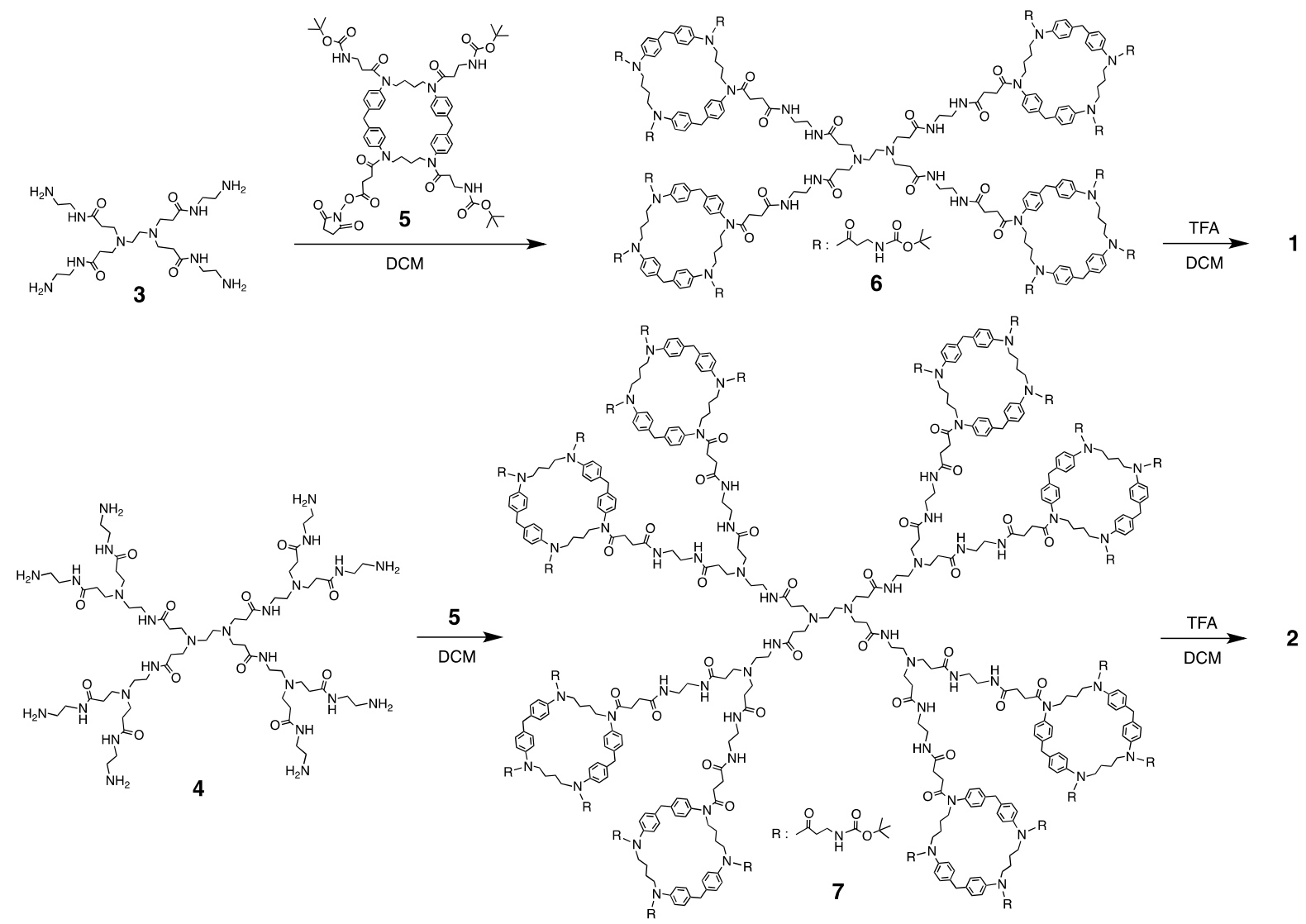

Scheme 1. Preparation of dendritic cyclophane tetramer 1 and octamer 2. 
(a)

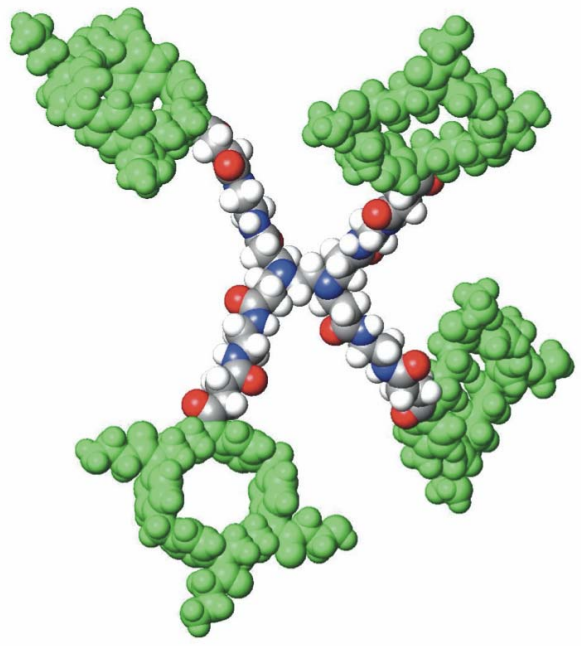

(b)

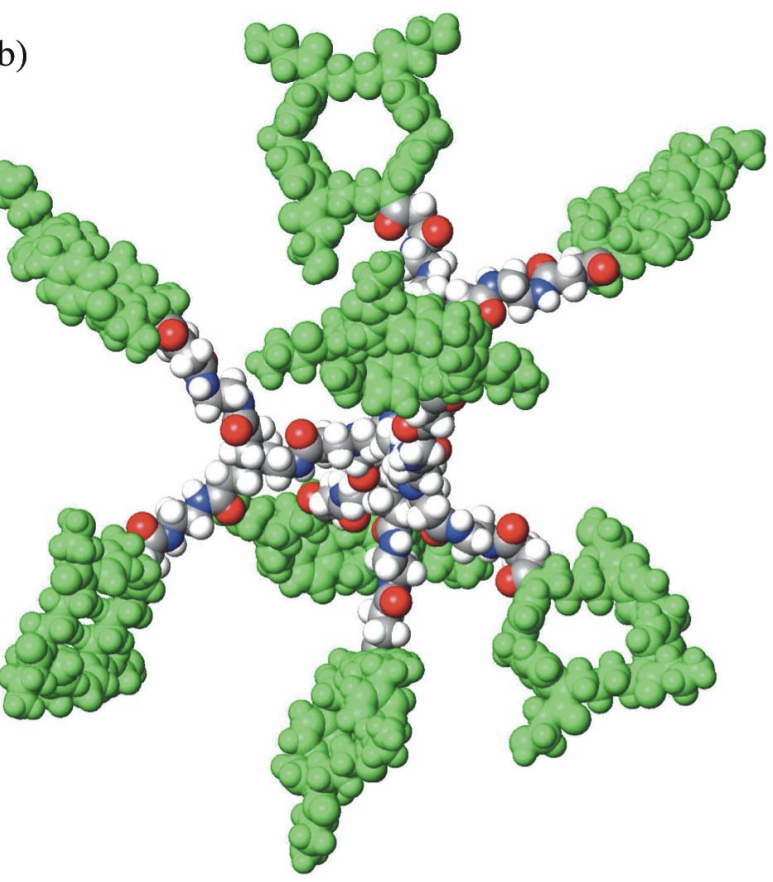

Figure 2. Computer-generated CPK models for 1(a) and 2(b). Cyclophanes are shown in green.

analysis.

Possible computer-generated CPK models [9] for 1 suggested that cyclophane tetramer 1 provides four hydrophobic cavities with a reasonably separated distance (Figure 2(a)). Similarly, compound 2 provide eight hydrophobic cavities for guest binding, respectively (Figure 2(b)). In addition, the computational evaluation reveals that each cyclophane oligomers display terminal hydrophilic groups on the periphery that are required for giving water solubility to cyclophanes, suggesting that these cyclophane oligomers were expected to act as water-soluble hosts.
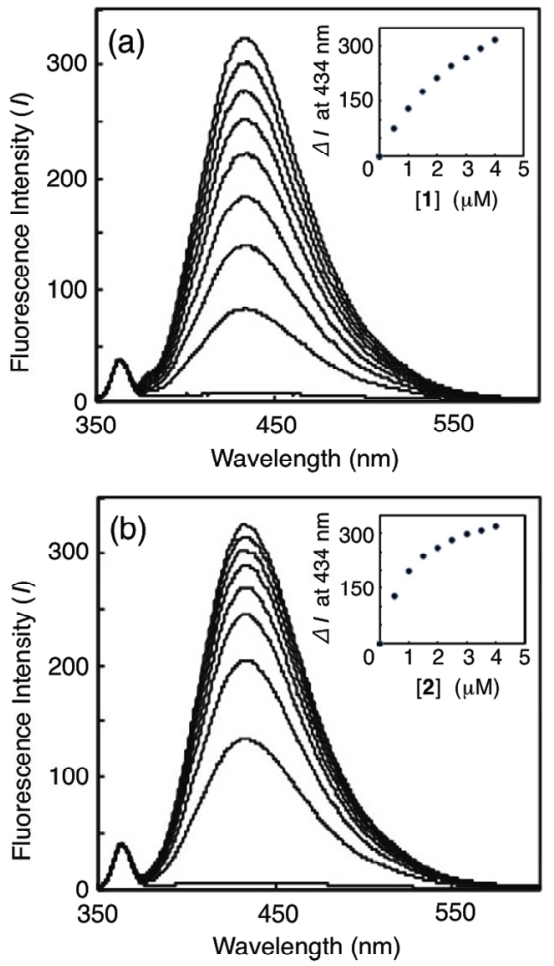

Figure 3. Fliorescence spectral changes for an aqueous solution of TNS upon addition of 1 (a) and 2 (b) in HEPES buffer at $298 \mathrm{~K}$; $[\mathrm{TNS}]=0.25 \mu \mathrm{M},[1]=[2]=0,0.5,1.0,1.5,2.0$, 2.5, 3.0, 3.5, and 4.0 $\mu \mathrm{M}$ (from bottom to top). Ex. $322 \mathrm{~nm}$. Inset: the corresponding titration curves.

\subsection{Guest-Binding of Cyclophanes}

The guest-binding affinity of $\mathbf{1}$ and $\mathbf{2}$ toward anionic fluorescent guests such as TNS and 6-anilinonaphthalene-2-sulfonate (2,6-ANS), whose emissions are sensitive to change in the microenvironments experienced by molecules [10], was examined by fluorescence spectroscopy in aqueous HEPES buffer $(0.01 \mathrm{M}, \mathrm{pH} 7.4,0.15 \mathrm{M}$ with $\mathrm{NaCl}$ ) at $298 \mathrm{~K}$. The fluorescence intensity originated from each guest increased along with a concomitant blue shift of the fluorescence maximum upon addition of the hosts as shown in Figure 3. Binding constants for the formation of inclusion complexes of the hosts with TNS and 2,6-ANS in a 1:1 molar ratio $(\mathrm{K})$ were evaluated on the basis of the Benesi-Hildebrand relationship [11] under the conditions at a large excess amount of the hosts, and are summarized in Table 1 together with the corresponding values for the monocyclic cyclophane (8) [3] (Figure 4). The K values of 1 and 2 with TNS were enhanced about 52- and 185-fold, respectively, relative to that of 8 . Since cyclophane oligomers 1 and $\mathbf{2}$ have four and eight binding sites, the guest-binding enhancements per binding site were estimated to be 13and 23-fold, respectively, which reflects multivalent effects in macrocycles. A similar enhancement on the 


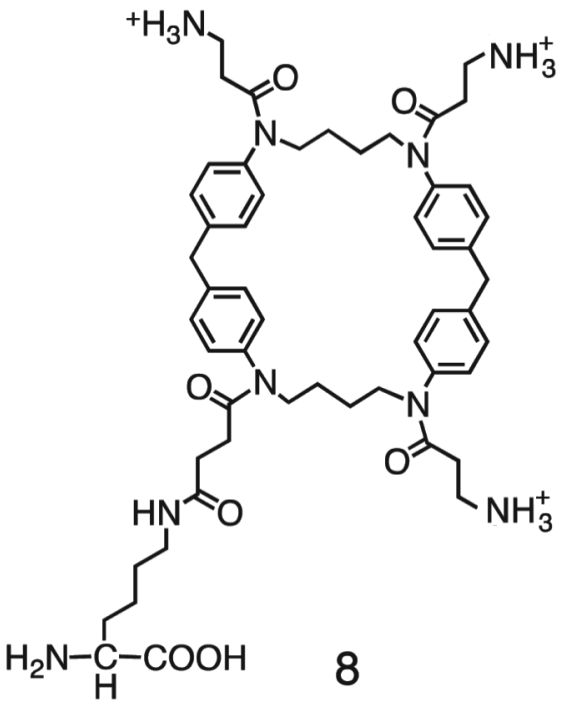

Figure 4. Monocyclic cyclophane 8.

Table 1. Binding constants $\left(\mathrm{K}\left(\mathrm{M}^{-1}\right)\right)$ for host-guest complexes of cyclophane oligomers 1 and 2 with TNS and 2, 6-ANS in HEPES buffer at $298 \mathrm{~K}^{\mathrm{a}}$.

\begin{tabular}{ccccc}
\hline \multirow{2}{*}{ Host } & \multicolumn{2}{c}{$\mathrm{K}\left(\mathrm{M}^{-1}\right)$} & \multicolumn{2}{c}{$\mathrm{K} / \mathrm{K}(\mathbf{8})$} \\
\cline { 2 - 5 } & $\mathrm{TNS}$ & $2,6-\mathrm{ANS}$ & $\mathrm{TNS}$ & $2,6-\mathrm{ANS}$ \\
\hline $\mathbf{2}$ & $9.6 \times 10^{5}$ & $6.5 \times 10^{5}$ & 185 & 128 \\
$\mathbf{1}$ & $2.7 \times 10^{5}$ & $2.0 \times 10^{5}$ & 52 & 39 \\
$\mathbf{8}^{\mathrm{b}}$ & $5.2 \times 10^{3}$ & $5.1 \times 10^{3}$ & & \\
\hline
\end{tabular}

${ }^{\mathrm{a}}$ Excitation: $322 \mathrm{~nm}$ (TNS); $318 \mathrm{~nm}$ (2,6-ANS). ${ }^{\mathrm{b}}$ Reference [3].

guest-binding behavior of $\mathbf{1}$ and $\mathbf{2}$ was observed when 2,6-ANS was employed as a guest (Table 1).

\section{Conclusion}

Dendritic cyclophane tetramer and octamer $\mathbf{1}$ and $\mathbf{2}$ were successfully prepared by aminolysis of succinimidyl ester of cyclophane with PAMAN dendrimers as a scaffold, followed by removal of the protecting groups in a fairly good yield. The present cyclophane oligomers demonstrate enhanced guest-binding affinities toward fluorescent guests in comparison with those of monocyclic cyclophane, reflecting multivalency effects in macrocycles. We believe that our concept on molecular design by the assembly of cyclophanes on a dendrimer framework provides a useful guidepost for preparation of divergenttype of cyclophane oligomers.

\section{Acknowledgements}

The present work is partially supported by Grant-in-Aid
(No. 24550166) from the Ministry of Education, Culture, Science, Sports and Technology of Japan.

\section{REFERENCES}

[1] Y. C. Lee, R. T. Lee, K. Rice, Y. Ichikawa and T.-C. Wong, "Topography of Binding Sites of Animal Lectins: Ligands' View," Pure \& Applied Chemistry, Vol. 63, No. 4, 1991, pp. 499-506. doi:10.1351/pac199163040499

[2] Y. C. Lee and R. T. Lee, "Carbohydrate-Protein Interactions: Basis of Glycobiology," Accounts of Chemical Research, Vol. 28, No. 8, 1995, pp. 321-327. doi:10.1021/ar00056a001

[3] O. Hayashida and T. Nakashima, "Synthesis of PeptideBased Cyclophane Oligomers Having Multivalently Enhanced Guest-Binding Affinity," Bulletin of the Chemical Society of Japan, Vol. 85, No. 6, 2013, pp. 715-723. doi:10.1246/bcsj.20120076

[4] O. Hayashida and T. Nakashima, "Synthesis of Cyclophane Dimer Using Cyclophane-Tethered Fmoc-Amino Acid Derivatives as a Multivalent Host," Chemistry Letters, Vol. 40, No. 2, 2011, pp. 134-135. doi:10.1246/cl.2011.134

[5] G. Franc and A. K. Kakkar, "Click Methodologies: Efficient, Simple and Greener Routes to Design Dendrimers," Chemical Society Reviews, Vol. 39, 2010, pp. 1536-1544. doi:10.1039/b913281n

[6] L. Albertazzi, M. Fernandez-Villamarin, R. Riguera and E. Fernandez-Megia, "Peripheral Functionalization of Dendrimers Regulates Internalization and Intracellular Trafficking in Living Cells," Bioconjugate Chemistry, Vol. 23, No. 5, 2012, pp. 1059-1068. doi: $10.1021 / \mathrm{bc} 300079 \mathrm{~h}$

[7] J. M. J. Fréchet, "Dendrimers and Supramolecular Chemistry," Proceedings of the National Academy of Sciences of the United States of America, Vol. 99, No. 8, 2002, 4782-4787.

[8] R. Esfand and D. A. Tomalia, "Poly(amidoamine) (PAMAM) Dendrimers: From Biomimicry to Drug Delivery and Biomedical Applications," Drug Discovery Today, Vol. 6, No. 8, 2001, pp. 427-436. doi:10.1016/S1359-6446(01)01757-3

[9] The calculations were carried out by Using Macromodel 7.5 Software.

[10] D. Matulis and R. Lovrien, "1-Anilino-8-naphthalene Sulfonate Anion-Protein Binding Depends Primarily on Ion Pair Formation," Biophysics Journal, Vol. 74, No. 1, 1998, pp. 422-429. doi:10.1016/S0006-3495(98)77799-9

[11] H. Benesi and J. Hildebrand, "A Spectrophotometric Investigation of the Interaction of Iodine with Aromatic Hydrocarbons," Journal of the American Chemical Society, Vol. 71, No. 8, 1949, pp. 2703-2707. doi: $10.1021 / \mathrm{ja} 01176 \mathrm{a} 030$ 